\title{
Ant-mediated anholocyclic overwintering of Prociphilus fraxini (Hemiptera: Aphididae) in Central Europe
}

\author{
Adrián Purkart, Miłosz Morawski, Adrian Masłowski \& Lukasz Depa*
}

Purkart, A., Morawski, M., Masłowski, A. \& Depa, Ł. 2019: Ant-mediated anholocyclic overwintering of Prociphilus fraxini (Hemiptera: Aphididae) in Central Europe. — Entomol. Fennica 30: 179-185. doi: https://doi.org/ 10.33338/ef.87175

The first observations of the aphid Prociphilus fraxini (Fabricius, 1777) being involved in a mutualistic relationship with the ant Prenolepis nitens (Mayr, 1853) in Europe is documented. Mutualism of an aphid generation living with the ants Prenolepis nitens and Lasius brunneus (Latreille, 1798) is discussed in reference to the possible development of an overwintering parthenogenetic population of the aphid, persisting on the roots of its secondary host, Picea abies, due to coevolution of the aphid with ants.

A. Purkart, Department of Zoology, Comenius University in Bratislava, Ilkovičova 6, Mlynská dolina, 84215 Bratislava, Slovakia; E-mail: mravce. info@gmail.com

M. Morawski, A. Masłowski \& Ł. Depa, Department of Zoology, Faculty of Biology and Environmental Protection, University of Silesia in Katowice, Bankowa 9, 40-007 Katowice, Poland; E-mails: milosz.f.morawski@gmail.com, amaslowski@us.edu.pl,*correspondingauthor:lukasz.depa@us.edu.pl

Received 7 January 2019, accepted 21 May 2019

\section{Introduction}

Mutualistic relationships with ants is a well-documented phenomenon influencing the life mode and feeding location of aphids (Shaposhnikow 1985). There are some aphid taxa with well-documented anholocyclic (i.e. permanently parthenogenetic) populations occurring throughout the year with ants due to strict mutualism: Trama spp., many species of the tribe Fordini from genera Forda, Geoica and Paracletus and some species of the genus Anoecia (Depa \& Wojciechowski 2008). These aphids most often live with common ant species, such as Lasius niger (Linnaeus, 1758) or L. flavus (Fabricius, 1782), and usually have an underground life mode as they are trophically associated with the roots of vari- ous plants. Therefore, it seems that environmental conditions in ant chambers under the soil surface enable aphids to exploit this niche (Heie 1980). In this respect, especially interesting seem to be the mutual interrelationships with the ant species living predominantly underground with deep excavations and which rarely forage above the soil surface, such as species belonging to the subgenus Chthonolasius or the enigmatic Prenolepis spp. There is some indication that these ant species strongly rely on mutualism with subterranean aphids. Relationships of this kind still remain strongly underrepresented in the field of studies on ant-aphid mutualism.

There are some 45 species belonging to the genus Prociphilus, all of them feeding on the woody parts of various plant families as their pri- 


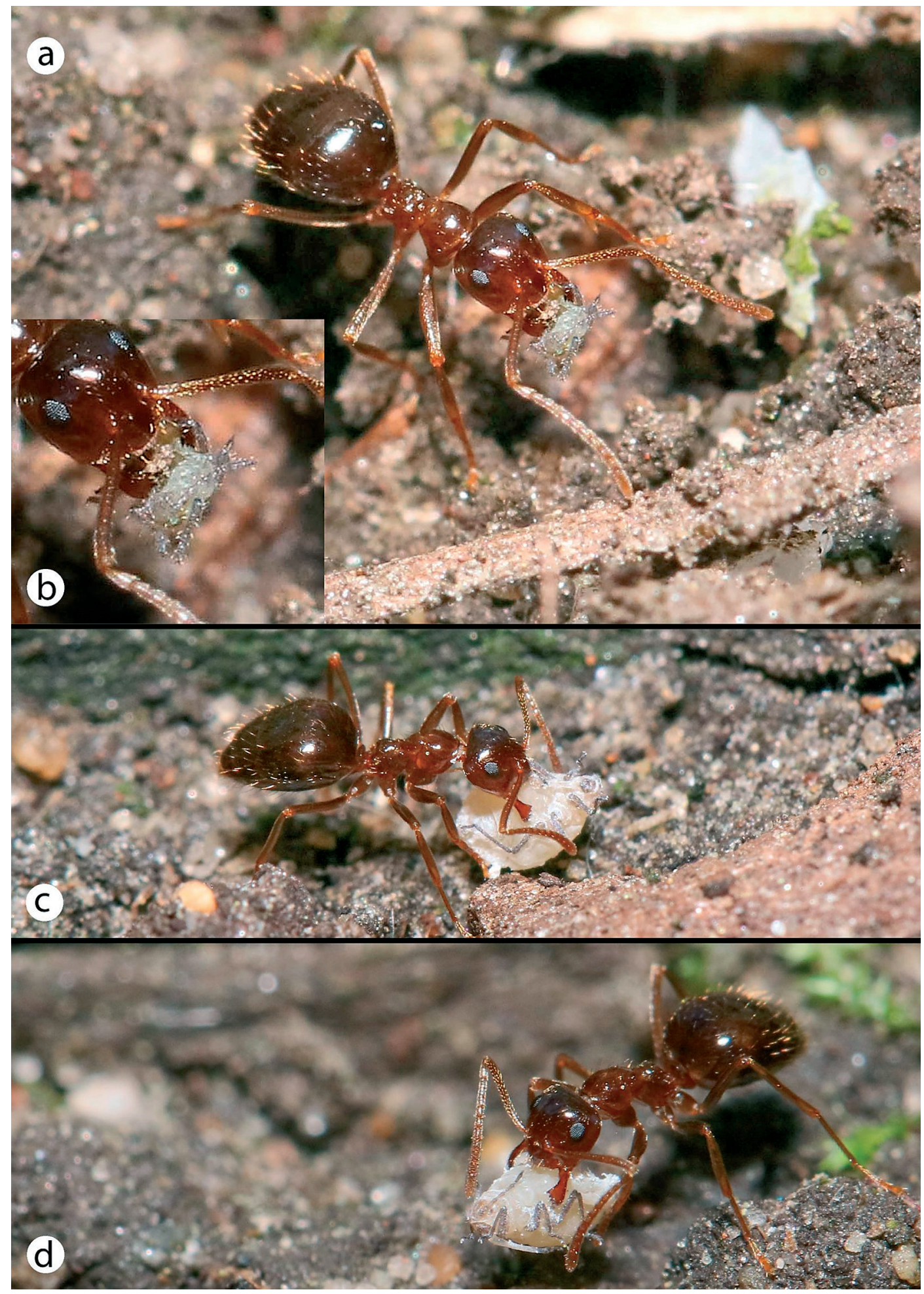

Fig. 1. Workers of Prenolepis nitens carrying larvae of Prociphilus fraxini in Bratislava. $-a, b .1^{\text {st }}$ instar larva. $-\mathrm{c}, \mathrm{d} .3^{\text {rd }}$ instar larvae of apterous viviparous females. 
mary host, where they reproduce sexually. Most of them are host alternating, with parthenogenetic summer generations feeding on the roots of coniferous trees as secondary hosts (Blackman \& Eastop 2018). Overwintering parthenogenetic populations of Prociphilus americanus (Walker, 1852) and other Prociphilus species are known from Northern America (Pike et al. 2012), where they are tended by ants even during the winter months (Smith 1969). These interactions mainly involve subterranean ant species of the genus Lasius (Ivens et al. 2018) and seem to be strict enough to result in the development of physiological and morphological adaptations in the aphids as a direct response to this kind of interrelationship. To date however, no such observations have been made in the case of European species of this genus.

A general concept is that Prociphilus (Prociphilus) spp. migrate from Fraxinus spp. to the roots of Abies spp., especially Abies alba, and in autumn, alate migrants fly back from Abies to Fraxinus to bear a sexual generation (i.e. males and oviparous females) (Heie 1980, Blackman \& Eastop 2018). There is no mention of any mutualistic relationship between ants and the aphid generation developing on the secondary summer host, despite the documented mutualism between ants and Prociphilus on their primary host (Heie 1980).

Here, we present new data indicating the possibility of this kind of mutualistic relationship between the host-alternating aphid species, Prociphilus fraxini (Fabricius, 1777), and both the European winter ant, Prenolepis nitens (Mayr, 1853), and the tree-dwelling brown garden ant, Lasius brunneus (Latreille, 1798). We discuss the possibility of $P$. fraxini developing as permanently parthenogenetic overwintering populations on a new secondary host, Picea abies.

\section{Materials and methods}

Observations were conducted in Poland and Slovakia, in 2014 and 2018. The first accidental observation in Poland in 2014 led to further observations in Poland, supported by extended observations by the first author in Slovakia in 2018.

Observed aphids and ants were collected and preserved in $70 \%$ ethanol for further studies. To ascertain the identification of the studied aphid specimens, which was crucial for further species recognition, the aphids were mounted and microscopic slides were prepared. The aphids were identified by the last author using the keys by Heie (1980). Mounted specimens were examined under a Nikon Eclipse E600 microscope and photographed using a Nikon DS-Fi camera. The microscopic slides are deposited in the entomological collection of the Department of Zoology, University of Silesia in Katowice (DZUS).

The observations of ant behaviour were photographed in situ using a Canon 80D camera fitted with a Canon $100 \mathrm{~mm}$ f2.8L macro lens. Determination of the ant specimens was undertaken by the first author using the keys of Seifert (2007). Mounted specimens are stored in the zoological collection of the Department of Zoology, Comenius University in Bratislava.

\section{Results}

The following observations were conducted:

10.5.2014: Bielsko-Biała, Poland; rotten log with a nest of Lasius brunneus, near the base of a trunk of Picea abies; three $1^{\text {st }}$ instar larvae determinable as $P$. fraxini; leg. M. Morawski, det. $Ł$. Depa. The aphids were kept alive in an ant chamber together with the brood.

10.4.2018: Botanical garden in Bratislava, Slovakia; three $3^{\text {rd }}$ instar apterous viviparous females and a single $1^{\text {st }}$ instar larva, determinable as $P$. fraxini, transferred by workers of Prenolepis nitens (Fig. 1a-d); leg. A. Purkart, det. Ł. Depa. Living aphids were carried in the mandibles by ant workers and transferred from one nesting site to another over a distance of some $0.7 \mathrm{~m}$. The aphids were often laid on the ground during the transport and then picked up again in the ant's mandibles somehow in a more comfortable position. Disturbed workers never dropped aphids on the ground, but tried to carry them to a safe place. Cleaning services offered by ants were not observed.

1.5.2018: Bielsko-Biała, Poland; rotten wood at the base of a trunk of Picea abies (Fig. 2); single 


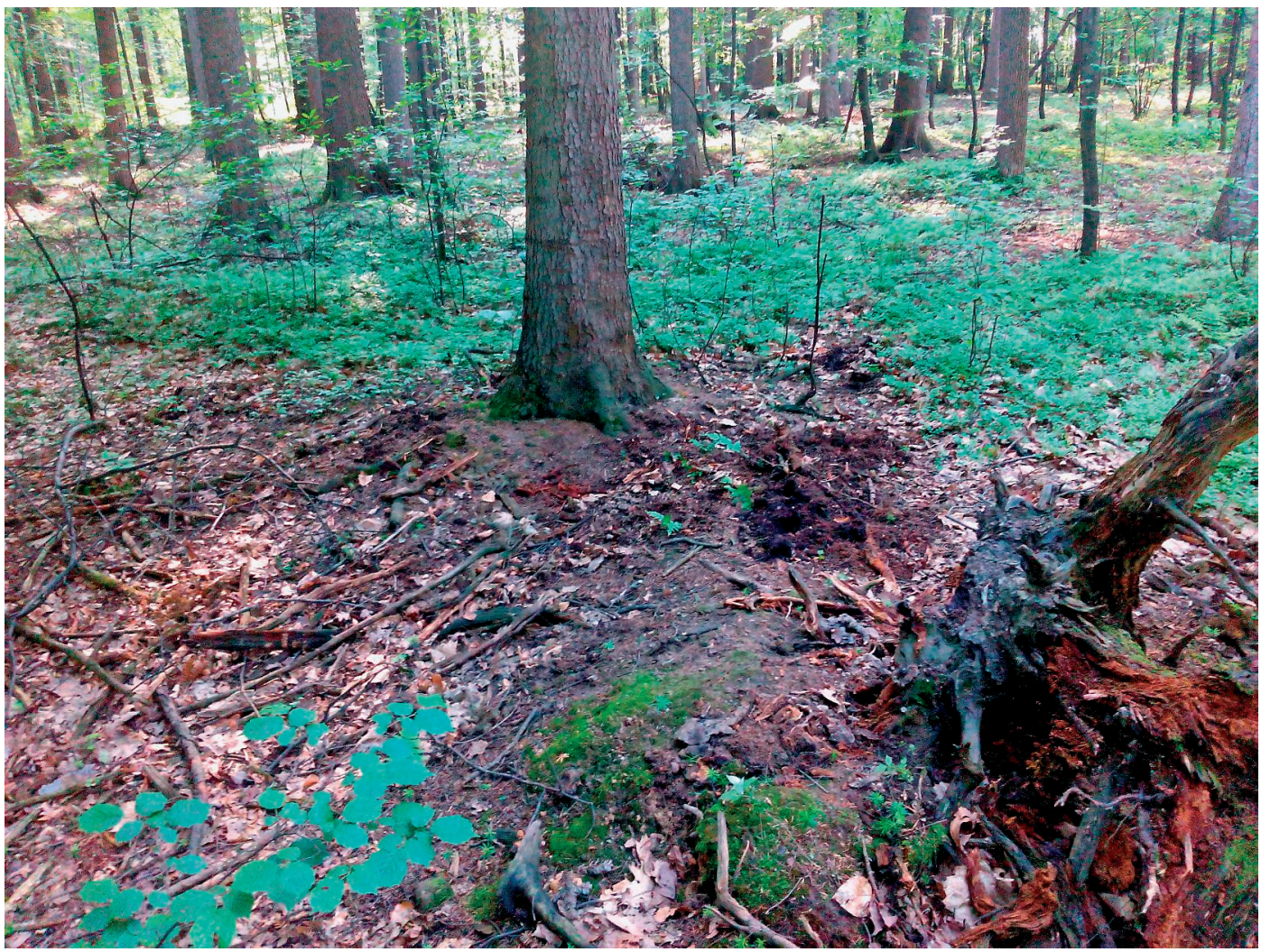

Fig. 2. Study site in Bielsko-Biała, Poland where a larva of Prociphilus fraxini in association with workers of Lasius brunneus was collected.

$1^{\text {st }}$ instar living larva determinable as $P$. fraxini (Fig. 3) associated with two workers of L. brunneus; leg. M. Morawski, det. Ł. Depa.

\section{Discussion}

The collected material posed some difficulties with determination. All of the $1^{\text {st }}$ instar larvae have a rostrum about as long as the body and two pairs of wax glands clearly visible on the head, anteriorly and posteriorly (Fig. 3), while $3^{\text {rd }}$ instar larvae all possess only the anterior ones. These features led to the determination of all samples as $P$. fraxini. However, the collected $1^{\text {st }}$ instar larvae have very long setae over the whole body, a feature which is supposed to occur only in the first generation larvae of $P$. bumeliae (Schrank, 1801) born on Abies by alate fundatrigeniae. However, because the morphology of larvae of the generations on secondary hosts of European species of Prociphilus is poorly understood, some degree of intraspecific variability may explain the observed differences.

The finding of $3^{\text {rd }}$ instar larvae near Bratislava as early as on $10^{\text {th }}$ April makes it impossible for them to have been born that year. Such a phenomenon would require the spring migration of alate fundatrigeniae to have occurred sometime at the end of March. This, in turn, would have required the hatching of fundatrices to have occurred sometime at the end of February.

Similarly in Poland, despite April 2018 being anomalously warm, the spring came very late due to a cold March, and the first adult alate fundatrigeniae were observed in Southern Poland, in the city center of Katowice (220 m a.s.1.), on May $7^{\text {th }}$, where they remained in the maternal aphid colony until at least May $11^{\text {th }}$. In the montane area of the collection of this study, the phenology of aphid development is delayed about a week to 10 days in comparison to Katowice. 


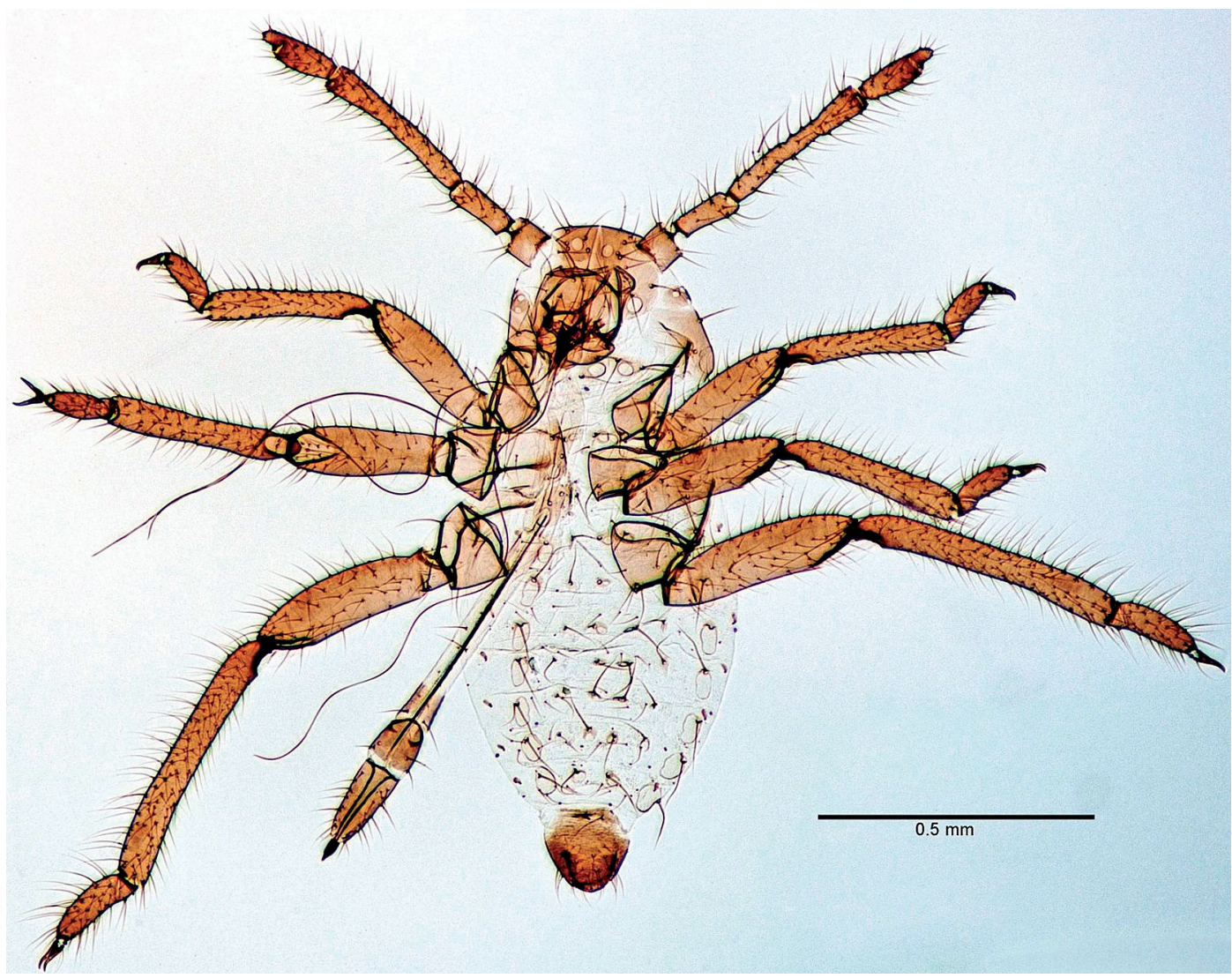

Fig. 3. Larva of Prociphilus fraxini collected in association with Lasius brunneus in Bielsko-Biała, Poland.

The presented data indicate that $P$. fraxini may produce an overwintering parthenogenetic population on the roots of their secondary host with the assistance of ants, or it may even overwinter in ant nests, as suggested by the finding of aphid larvae within an ant brood. According to Heie (1980), stout and long setae on the body of $1^{\text {st }}$ instar larvae would suggest that these are the first generation of alate fundatrigeniae, but no alate specimens were found. In addition, the transfer of aphids by ant workers when moving to different nesting sites shows a strong affiliation between aphids and ants. Such an affiliation is known to occur in a few North American species of Prociphilus, e.g. P. americanus, P. tesellatus (Fitch, 1851) and $P$. erigeronensis (Thomas, 1879) (Smith 1969, Blackman \& Eastop 2018). Recent studies by Ivens et al. (2018) also indicate a very deep mutualistic relationship between Prociphilus spp. and tending ants of the genus Lasius. It should not be surprising, therefore, that in Central Europe a similar phenomenon may occur.

Aphids living on roots are relatively poorly studied and the life mode of the European Prociphilus spp. might not have been properly recognized by researchers. Furthermore, the life cycles of many species in this genus remain unknown (Blackman \& Eastop 2018). It is difficult to speculate on whether such populations may thrive through years in permanent anholocycly with seasonal production of alate sexuparae, or perhaps are only a part of a 2-year cycle, similar to that in the tribe Fordini. In the latter, permanent parthenogenesis exists in areas beyond the range of primary hosts (Pistacia spp.) (Ortiz-Rivas et al. 2009).

In Europe, Fraxinus occurs in most of the territory of $P$. fraxini but the range of Abies alba is largely restricted to montane areas. This is the opposite situation to that in the tribe Fordini, in that the secondary host of $P$. fraxini is less widespread 
than the primary one. It is most probable that we observed a population on a new secondary host, Picea abies, as there were no A. alba trees or seedlings near the site. The plant species Picea abies is exploited by the aphid species Prociphilus (Stagona) xylostei (De Geer, 1773) and the related genera Pachypappella and Pachypappa. Aphids of the latter genera may overwinter on the roots of Picea (Heie 1980), where they are visited by ants. Hence, the utilization of Picea abies as a secondary host by $P$. fraxini, including overwintering on the same host, seems to be both plausible and in line with the adaptations seen in related species and genera.

This mutualistic relationship between Prociphilus fraxini aphids and Prenolepis nitens ants is the first observed in Europe. The very cryptic life mode of the latter makes studies of this ant species difficult. It seems that in the observation locations this species prefers stony soils, where in spring it is easily found beneath stones, but during later seasons the ants hide deeper in the ground, where they probably live with aphids in absolute safety. Little is known about the food resources of Prenolepis spp., although LaPolla et al. (2010) show a possibility of utilizing honeydew from coccids. Lörinczi (2016) states that the food of $P$. nitens mainly consists of liquids rich in carbohydrates, such as honeydew, but no details on possibly exploited aphid species are given.

Data on an American relative, Prenolepis imparis (Say, 1836), shows a curious adaptation of feeding in cool seasons and aestivation in summer with storage of nutrients in worker fat bodies in chambers very deep in the soil (even more than $3 \mathrm{~m}$ deep, not shallower than $0.6 \mathrm{~m}$ !) (Tschinkel 1987).

Due to the similarly uncertain structure of the underground nests and secretive underground lifestyle of $P$. imparis and the European $P$. nitens ants, there is a good chance that ant-aphid associations exist also in the American $P$. imparis nests. The possibility that $P$. nitens may exploit aphids feeding deep in the ground on tree roots may be very plausible in the light of the present observations. Furthermore, fossil material from amber inclusions may indicate that the ecological relationships of this genus with ants (Perkovsky 2011) is an old one, existing as early as the Late Eocene (ca. 30-40 mya).
Interestingly, the inclusion comprised a Prenolepis ant and a Germaraphis aphid, representative of the same subfamily Eriosomatinae as Prociphilus. This certainly raises the possibility of coevolution between the aphid generation on a gymnosperm secondary host and ancient species of Prenolepis, leading both to develop a cryptic subterranean life mode on the roots of trees.

Acknowledgments. The study was financially supported by the project VEGA 2/0012/17. We wish to thank Marzena Zmarzły, Krzysztof Kudła and Artur Taszakowski for help in preparation of figures. We also thank Julian Hodgson for suggestions and linguistic improvements of the manuscript.

\section{References}

Blackman, R. L. \& Eastop, V. F. 2018: Aphids on the world's plants. An online identification and information guide. www.aphidsonworldsplants.info (accessed on 18.11.2018)

Depa, Ł. \& Wojciechowski, W. 2008: Ant-root aphid relations in different plant associations. - Polish Journal of Entomology 77: 151-163.

Heie, O. E. 1980: The Aphidoidea (Hemiptera) of Fennoscandia and Denmark I. - Fauna Entomologica Scandinavica 9, $236 \mathrm{pp}$.

Ivens, A. B. F., Gadau, A., Kiers, E. T. \& Kronauer, D. J. C. 2018: Can social partnerships influence the microbiome? Insights from ant farmers and their trophobiont mutualists. - Molecular Ecology 27(8): 1898 1914. doi: https://doi.org/10.1111/mec.14506

LaPolla, J. S., Brady, S. G. \& Shattuck, S. O. 2010: Phylogeny and taxonomy of the Prenolepis genus group of ants (Hymenoptera: Formicidae). — Systematic Entomology 35(1): 118-131. doi: https://doi.org/10.1111/ j.1365-3113.2009.00492.x

Lörinczi, G. 2016: Winter activity of the European false honeypot ant, Prenolepis nitens (Mayr, 1853). — Insectes Sociaux 63(1): 193-197. doi: https://doi.org/ 10.1007/s00040-015-0437-z

Ortiz-Rivas, B., Martínez-Torres, D. \& Hidalgo, N. P. 2009: Molecular phylogeny of Iberian Fordini (Aphididae: Eriosomatinae): implications for the taxonomy of genera Forda and Paracletus. - Systematic Entomology 34: 293-306. doi: https://doi.org/10.1111/ j.1365-3113.2008.00464.x

Perkovsky, E. E. 2011: Syninclusions of the Eocene winter ant Prenolepis henshei (Hymenoptera: Formicidae) and Germaraphis aphids (Hemiptera: Eriosomatidae) in Late Eocene Baltic and Rovno amber: some implications. - Russian Entomological Journal 20: 303313. doi: https://doi.org/10.15298/rusentj.20.3.15

Pike, K. S., Graf, G., Foottit, R. G., Maw, H. E. L., von Dohlen, C., Harpel, J., Pantoja, A., Emmert, S. \& Ha- 
gerty, A. M. 2012: Eriosomatine aphids (Hemiptera: Aphididae: Eriosomatinae) associated with moss and roots of conifer and willow in forests of the Pacific Northwest of North America. - Canadian Entomologist 144: 555-576. doi:10.4039/tce.2012.49

Seifert, B. 2007: Die Ameisen Mittel- und Nordeuropas. — Lutra \& Vertriebsgesellschaft, Görlitz. 368 pp.

Shaposhnikov, G. Ch. 1985: The main features of the evolution of aphids. - In: Szelegiewicz, H. (ed.), Evolution and biosystematics of aphids: p. 19-99. Proceedings of the International Aphidological Symposium at Jabłonna, 5-11 April, 1981. Polish Academy of Sciences, Institute of Zoology, Warsaw. 510 pp.

Smith, C. F. 1969: Pemphiginae associated with the roots of conifers in North America (Homoptera: Aphididae). - Annals of the Entomological Society of America 62(5): 1128-1152. doi: https://doi.org/10.1093/ aesa/62.5.1128

Tschinkel, W. R. 1987: Seasonal life history and nest architecture of a winter-active ant Prenolepis imparis. - Insectes Sociaux 34(3): 143-164. doi: https:// doi.org/10.1007/BF02224081 